\title{
Correction to: Landscape Planning with Ecosystem Services
}

Christina von Haaren, Andrew A. Lovett, and Christian Albert

\section{Correction to: \\ C. von Haaren et al. (eds.), Landscape Planning with Ecosystem Services, Landscape Series 24, https://doi.org/10.1007/978-94-024-1681-7}

Fig. 3.3 in Chapter 3 and Fig. 30.1 in Chapter 30 were initially published with errors. The correct presentation is given here. 


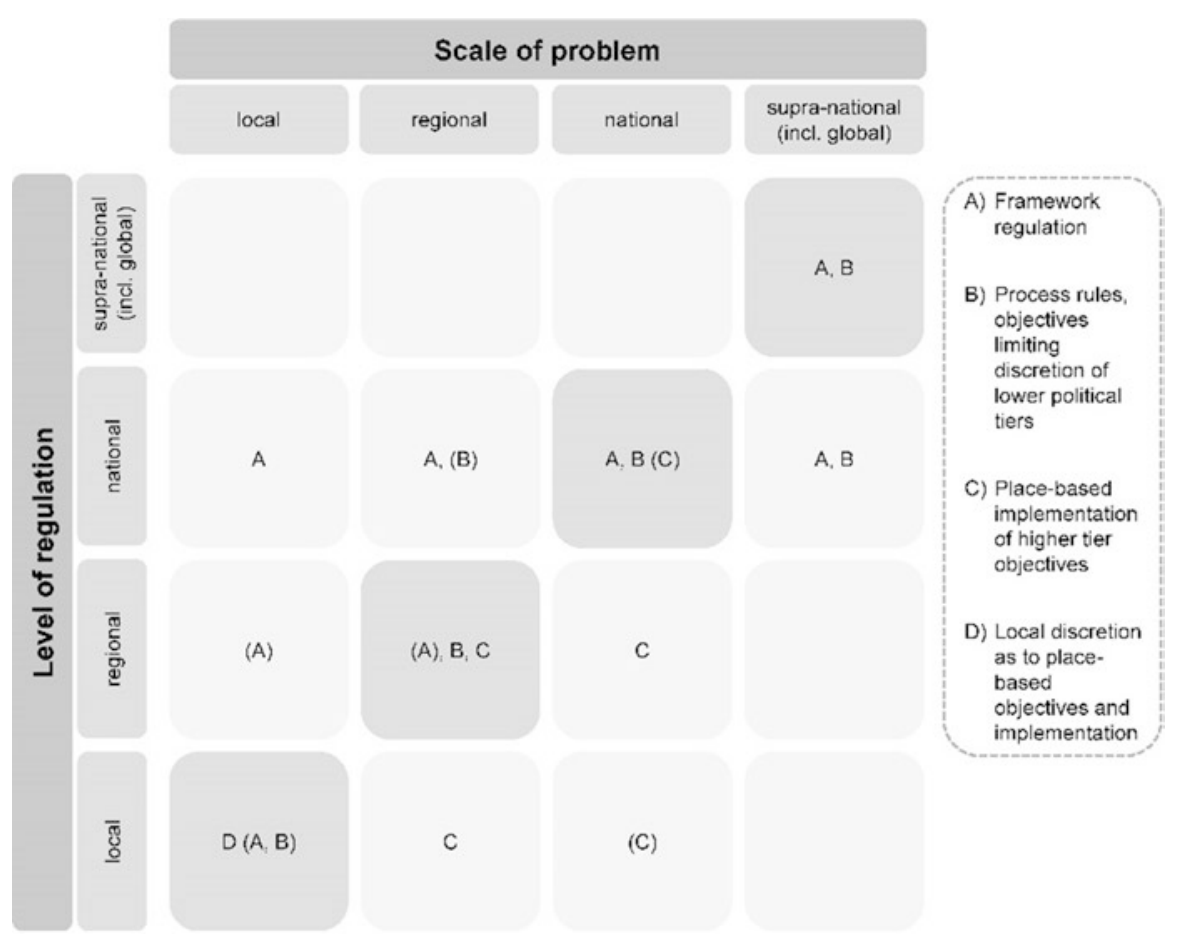

Fig. 3.3 Defining the decision space of landscape planning. Tasks on different planning tiers are determined by the scale of the problem and associated responsibilities. Projects with crossboundary impacts or trans-boundary ecosystems (such as river catchments) need to be considered at higher planning tiers with authority that covers the whole relevant area (von Haaren 2016: 171, amended) 


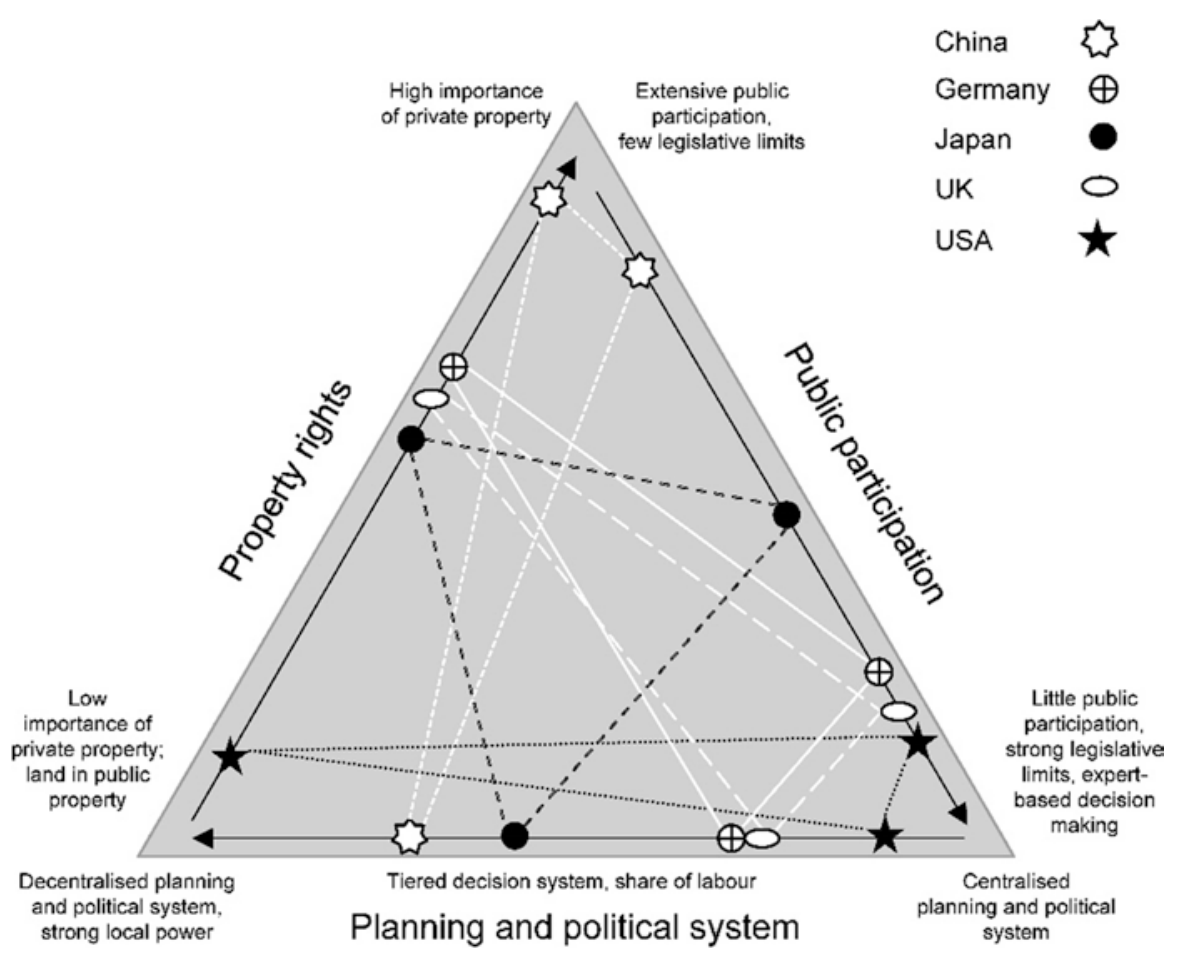

Fig. 30.1 A schematic classification of framing conditions for environmental planning in five example countries. The conditions may be decisive for the importance of economic evaluations, the binding character of objectives, the scope and role of public participation and the scale and delineation of the scope of planning. We are aware of the internal differentiation in the USA, where the preconditions may differ a lot among the states. Nevertheless there are some general frame conditions shared by all US states based on the US legal system and on federal policies 